\title{
APLICACIONES GEOTECNOLOGICAS AL ESTUDIO ARQUEOLÓGICO DEL NE DE MENDOZA
}

\author{
(APPLICATIONS GEOTECNOLOGICAS \\ TO THE ARCHAEOLOGICAL STUDY OF THE NE DE MENDOZA)
}

\author{
Prof. Fernando Hernandez \\ Becario graduado, SECyT, UNCuyo. josefernah@gmail.com \\ Lic. Horacio Chiavazza \\ Inv. SECyT, FFyL, UNCuyo, Mendoza. hchiavazza@gmail.com
}

\section{Resumen}

Las modernas técnicas geográficas manifestaron un alcance en los últimos años, que traspasa los límites de la disciplina geográfica y son aplicadas a diversas áreas del conocimiento científico.

Incorporamos la aplicación de técnicas como teledetección, georreferenciación espacial y sistemas de información geográfica en el marco del proyecto titulado Ambiente, cultura y relaciones interétnicas en el área huarpe del NE de Mendoza durante el siglo XVIII. Continuidades y transformaciones que contribuyeron a los procesos de articulación social.

El presente artículo refleja los resultados de las tareas de integración entre la Arqueología y la Geografía con el objetivo común de contribuir al conocimiento del pasado mendocino.

\section{Summary}

The modern ones technical geographical they manifested a reach in the last years that it passes over the limits of the geographical discipline and they are applied to diverse areas of the scientific knowledge.

We incorporate the application of technical as teledetección, space georeferenciación and geographical systems of information in the mark of the project titled Environment, culture and relationships interétnicas in the area huarpe of Mendoza's NE during the XVIII century. Continuities and transformations that contributed to the processes of social articulation.

The present article reflects the results of the integration tasks between the Archaeology and the Geography in the common objective of contributing to the knowledge of the last mendocino.

Palabras claves: teledetección, georeferenciación espacial, ambiente, cultura, Huarpes. Key words: teledetección, space georeferenciación, environment, culture, Huarpes.

\section{Introducción}

Las variaciones en la disponibilidad de recursos poseen una variable relación con la organización económica establecida en diferentes lapsos históricos, que responde tanto a modelos basados en la producción, como a aquellos modelos basados en la extracción de recursos para subsistir.

Nos interesa integrar en el análisis de la espacialidad de estas relaciones a la Geografía, como la disciplina que brinda la posibilidad de aportar técnicas específicas al campo de la Arqueología. La aplicación de Sistemas de Posicionamiento Global -GPS-, la teledetección a través de imágenes satelitales y sistemas de software específicos, posibilitan el manejo integrado de grandes volúmenes de datos. De esta manera, en nuestro trabajo se busca integrar información histórica obtenida a través de 
documentos y mapas históricos, con imágenes satelitales georreferenciadas, y con esto facilitar las tareas de prospección arqueológica.

El objetivo se vincula con dos ejes fundamentales, por un lado, aportar herramientas y datos que ayuden a la comprensión de las variaciones producidas en la disponibilidad de recursos para la subsistencia de sociedades pretéritas en el NE de la provincia y, al mismo tiempo, aportar conocimientos a los procesos de ocupación del territorio por parte de las sociedades indígenas y europeas. Centramos nuestro análisis en la región de la llanura del NE mendocino en general y, en particular, a la franja que en sentido norte sur es adyacente al río Desaguadero, con límites al norte el complejo de lagunas y río San Juan, al oeste la llanura de la travesía y al sur el río Tunuyán. El lapso temporal que abarcamos corresponde al s. XVIII.

La disciplina geográfica debe enfrentar una profunda división entre la Geografía Física y la Geografía Humana. Hecho que se evidencia no solamente en artículos de investigación, sino también en líneas editoriales (1) (Capel, H. 1998) y estructuras de las carreras de formación universitaria. Con este trabajo apuntamos a salir de esta dicotomía, comprendiendo que los elementos físicos y humanos conforman de manera integrada la individualidad de los territorios y transforman así un paisaje con significaciones que varían en el tiempo.

Define nuestro enfoque la posibilidad del trabajo interdisciplinario, entendido como el desarrollo de tareas geográficas conjuntamente al desarrollo de tareas vinculadas con la Historia en general y la Arqueología en particular. Desde esta posición, consideramos necesario precisar algunas categorías conceptuales básicas.

Entendemos al espacio como un producto social lo que permite otorgar el sentido que posee la acción humana en la organización del territorio. Los modelos de ocupación del espacio así como el aprovechamiento del mismo y los desequilibrios territoriales presentes y visibles actualmente, comparten sus causas en la decisión de los seres humanos de actuar sobre el territorio generando estos fenómenos. Por lo que, posicionarnos en este enfoque geográfico significa concebir el mundo real como: “...una totalidad constituida por partes interconexas entre sí, no como una simple suma de las partes o su combinación casual, sino como estructura relacional compleja" (Vagaggini y Dematteis, 1977:8)

Desde esta perspectiva, al analizar la realidad espacial las estructuras configuradas son construidas a partir de las relaciones existentes entre las partes que constituyen esa realidad. Las relaciones que se dan entre las partes no necesariamente son armónicas, por lo que otorgan dinamismo a la estructura que cambia continuamente a través de la transformación de las relaciones que la constituyen, en un principio dialéctico. De este modo, la realidad no es lo que es sino lo que deviene; y en este devenirse los espacios se constituyen en paisajes con dimensiones temporales impresas en rasgos materiales.

La noción de paisaje geográfico adquiere en nuestro trabajo un significado distinto. En términos de Criado Boado (1999), la Arqueología del Paisaje se presenta actualmente como una propuesta para estudiar el sentido de la espacialidad humana desde su materialidad, para aproximarse a la interpretación del registro arqueológico. Desde este punto de vista, el paisaje se define como:

“...un producto socio-cultural creado por la objetivación, sobre el medio y en términos espaciales, de la acción social tanto de carácter material como imaginario. Esta acción social está constituida tanto por las prácticas sociales (Ej.: la acción social de carácter intencional; procesos de trabajo, utilización de técnicas, ritos, etc) como por la vida social misma (Ej.: la acción social no instintiva, la espontánea, determinada por los imperativos biológicos de la naturaleza humana y por la satisfacción de estos)" (Criado Boado, 1999 : 8) 
Por lo tanto, para cumplir el objetivo de explicar el comportamiento humano en el mundo es necesario entender cómo las sociedades se adaptan, modifican, utilizan, organizan y comprenden el espacio.

\section{Materiales y Métodos}

El avance tecnológico alcanzado en las últimas cuatro décadas ofrece, a la ciencia en su conjunto, modernas y complejas técnicas para realizar investigaciones espaciales. Un Sistema de Información Geográfica (SIG) es entendido como:

“...un sistema de hardware, software y procedimientos elaborados para facilitar la obtención, gestión, manipulación, análisis, modelado, representación y salida de datos espacialmente referenciados, para resolver problemas complejos de planificación y gestión" (Bosque Sendra, 1992 : 21)

De esta manera, los SIG permiten realizar investigaciones interdisciplinarias en un espacio determinado (urbano y/o rural) y, al mismo tiempo, sintetizar en forma relacionada, los resultados de una investigación para la futura aplicación en gestión y/o planificación.

En el año 1962 se implementó el primer sistema de información geográfico en Canadá y se orientaba al análisis de los recursos naturales a escala mundial. Con el transcurso del tiempo se comenzaron a utilizar en cualquier disciplina científica que necesite reflejar datos integrados espacialmente, elaborando cartografía específica. De este modo, los sistemas de información geográfica traspasaron los límites de la Geografía y comenzaron a ser aplicados a otras disciplinas.

En Arqueología, el uso de los SIG es reciente. En la década de los 70' comienzan a difundirse en Estados Unidos y Europa proyectos arqueológicos que incorporan esta herramienta en sus investigaciones.(Carmona, 2004). En Latinoamérica los trabajos arqueológicos con SIG no fueron muy difundidos hasta comienzos de la década de 1990. En los últimos 10 años, se experimentó un incremento de su utilización en investigaciones que generalmente están orientados a:

- Elaboración de cartografía.

- Elaboración de modelos de paisaje.

Nuestro trabajo se apoya en una fuerte orientación técnica, por lo tanto la metodología aplicada responde a la utilización de diversos programas informáticos o software con los que trabajamos durante estas etapas. El software de base utilizado para los SIG, es Arc View (versión 3.2), un programa que permite el análisis y visualización de datos espaciales mediante "shapes" o coberturas digitales referidas a variables físicas y humanas del territorio. En segundo lugar, la búsqueda y obtención de imágenes satelitales de nuestra área de estudio fue realizada a través de la red internet. Esta búsqueda se orientó hacia imágenes Landsat, que comprendieran el sector NE de Mendoza. Estas imágenes fueron seleccionadas, entre otras, por su accesibilidad, escala y calidad de la imagen en general. El análisis de estas imágenes satelitales y la georreferenciación se realizó a través del programa de software "Mrs SID". Por último, el programa de software "Auto CAD", se utilizó para la digitalización de documentos cartográficos.

Como documento histórico de base utilizamos el mapa elaborado por Ximenez Inguanzó en el año 1789, y recuperado en una publicación titulada "Arqueología y Etnografía de las lagunas de Guanacache" de M. Vignati (1953), también por Abraham y Prieto (1981) y por Chiavazza et al (2002). Entendemos que uno de los puntos valiosos de este mapa descansa en el enfoque con que se elaboró ya que permite "...comprender el espacio como un continuum que va más allá de la ciudad y representa el entorno donde la misma se inserta" (Chiavazza et al, 2002: 97). Las cualidades de este documento histórico, útiles a la 
investigación arqueológica, fueron ya señaladas en otros trabajos (Chiavazza et al, 2002, Prieto y Abraham, 1981) entre las que remarcamos la claridad de referencias otorgadas por el autor del mapa, así como por la precisión y cantidad de detalles observables en la misma, ya que no solamente se hace referencia a los pueblos indígenas acotados temporalmente a la segunda mitad del siglo XVIII, sino también a la posición de la ciudad de Mendoza, los caminos de indios, las diferentes lagunas que conforman el complejo lagunar de Guanacache y los ríos Mendoza y Tunuyán e incluso las variaciones de su cauce.

Nuestro interés descansa en recuperar la espacialidad de las relaciones reflejadas a través de los aspectos físicos y humanos que fuera observada por Ximenez Inguanzó durante el viaje de reconocimiento de las Lagunas, en el año 1789. Este viaje se inicia desde el puente en construcción sobre el río Desaguadero y tiene como objetivo conocer la dinámica ambiental y elaborar un relevamiento poblacional del área. Junto a otros tres mapas, también elaborados durante este recorrido, permiten detallar la evolución del complejo lacustre (Chiavazza et al, 2002).

La riqueza de información del cuaderno de viaje que acompaña a estos mapas resulta apreciable ya que da cuenta no solamente de la situación hídrica que presentaba la llanura del NE Mendocino para fines del s. XVIII, sino también de las características físicas de las áreas recorridas a través del itinerario de viaje, como así también datos de los grupos humanos que ocupaban estas regiones.

Consideramos que el cruce de la información documental con la carta histórica y su traslape con imágenes de satélite resultan claves en la elaboración de hipótesis que pueden ser corroboradas desde la Arqueología. (Abraham y Prieto, 1981, Chiavazza, 2001)

\section{Resultados preliminares}

Mencionamos anteriormente, la riqueza de información que posee un documento histórico como lo es el cuaderno de viaje de Vignati M. El mapa que se adjunta en mencionado documento, correspondiente al s. XVIII, resulta igualmente rico en información ya que contiene referencias concretas a los aspectos naturales como (ver figura 1 ):

- Ríos existentes: forma de representación lineal. Se mencionan los ríos Mendoza y Tunuyán donde se destaca que el Mendoza ya orienta su curso hacia el norte (Vignati 1953, Abraham y Prieto 1981 y Chiavazza 2001).

- Lagunas existentes: forma de representación areal. Valiosas porque facilitan la georreferenciación de sectores lagunares, bañados y matorrales. Se mencionan numerosas lagunas, "laguna de Silverio", "laguna y sierra que Ilaman de las Quijadas", "laguna de los Chomes", "la lagunilla", "Iaguna de Santo", "Lagunas del Rosario", etc. Algunas de estas conservan en la actualidad las denominaciones históricas.

- Geomorfología: forma de representación areal, También útiles para la georreferenciación se reconocen entre otros las "Iomas de Lunlunta", "el médano de Alto Grande" y la "sierra de Las Quijadas".

- Bañados y lagunas: forma de representación areal. con las cotas de profundidad consignadas, y comentarios acerca de las características de los vegetales presentes en los alrededores. ej: "totoral"

Entre los aspectos humanos observables en el mapa tenemos (ver figura 1):

-Pueblos indígenas: forma de representación puntual. Considerados esenciales para las tareas de georreferenciación en imágenes satelitales, ya que permitirá aproximarnos a la posición exacta de los mismos y con esto proponer tareas de prospección arqueológica. Se mencionan algunos grupos que no son denominados Huarpes, sino con otras denominaciones, por ejemplo: "población que llaman los chañares", y el caso de la "población de los Chomes" que si bien no son mencionados en este mapa, si lo 
son en documentos históricos donde figuran como encomendados a los españoles (Prieto $\mathrm{M}$. y $\mathrm{H}$. Chiavazza. 2006) y que probablemente coincida con los habitantes de Laguna de los Chomes.

-Caminos de indios: forma de representación lineal. Resultan interesantes de analizar ya que permiten proponer una red jerárquica de caminos y comunicaciones entre distintos centros poblados o caseríos.

-Ciudad de Mendoza: forma de representación areal, utilizando como variable visual los puntos.

-Localidades y Puestos: forma de representación puntual. En diversos casos conservan en la actualidad las denominaciones históricas, en otros casos se conoce la transformación del nombre histórico. Ej. "capilla de Corocorto" hace referencia a la actual La Paz. Algunos puestos que se localizan son: "Capilla de San Miguel", "Capilla del Rosario", "Punta del agua", "Cruz de Jume", "Las playas", etc.

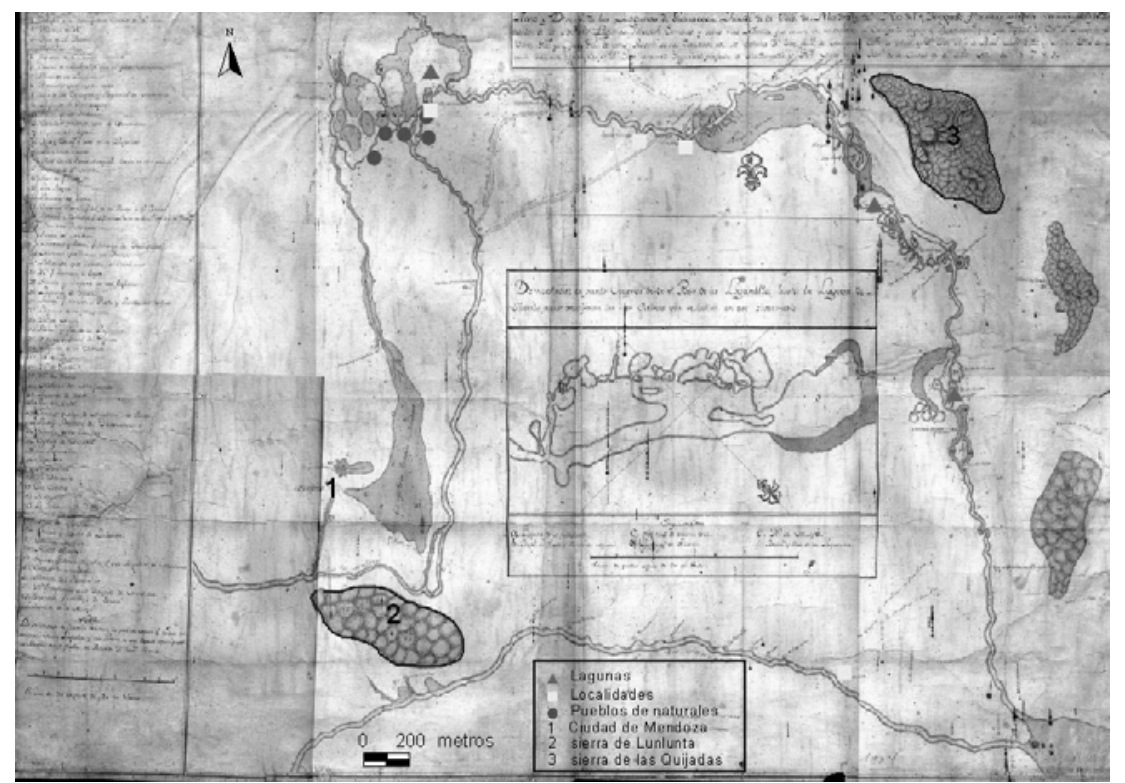

Figura 1: Mapa 1789 con aspectos físicos y humanos

La imagen de satélite georreferenciada permitió localizar estos aspectos naturales y humanos y detectar, al mismo tiempo, características vegetales, hídricas y geoformas del terreno (ver figura 2). La imagen landsat utilizada corresponde al norte de la provincia de Mendoza, y abarca desde la Cordillera Principal hasta el oeste de la provincia de San Luis.

En nuestro trabajo incorporamos coberturas digitales georreferenciadas correspondientes a ríos, puestos actuales, diques, oasis norte y centro. De esta manera, ubicamos en la imagen estos elementos naturales y los utilizamos como referencia espacial para poder identificar los aspectos (naturales y humanos) mencionados en la carta histórica de X. Inguanzó. 


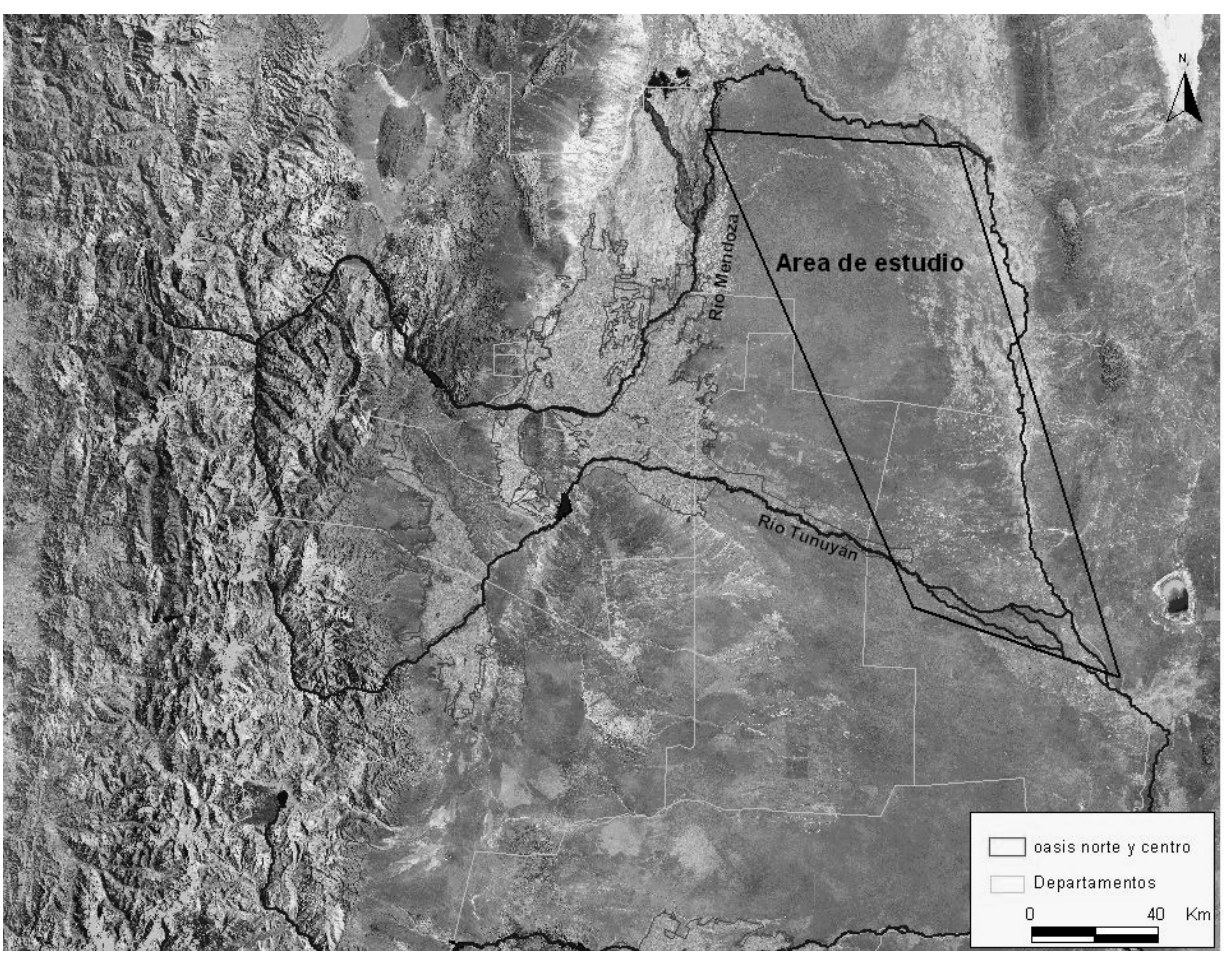

Figura 2: Imagen de satélite y coberturas digitales georreferenciadas

Una vez identificados estos aspectos se procedió a superponer el mapa de Ximenez Inguanzó con la imagen satelital landsat (ver figura 3). De esta manera, fue posible otorgar coordenadas geográficas al mapa histórico y con esto a los aspectos, tanto físicos como humanos, en él representados en 1789. Esta georeferencia permite aproximarnos a la posición que presentaban a fines del siglo XVIII.

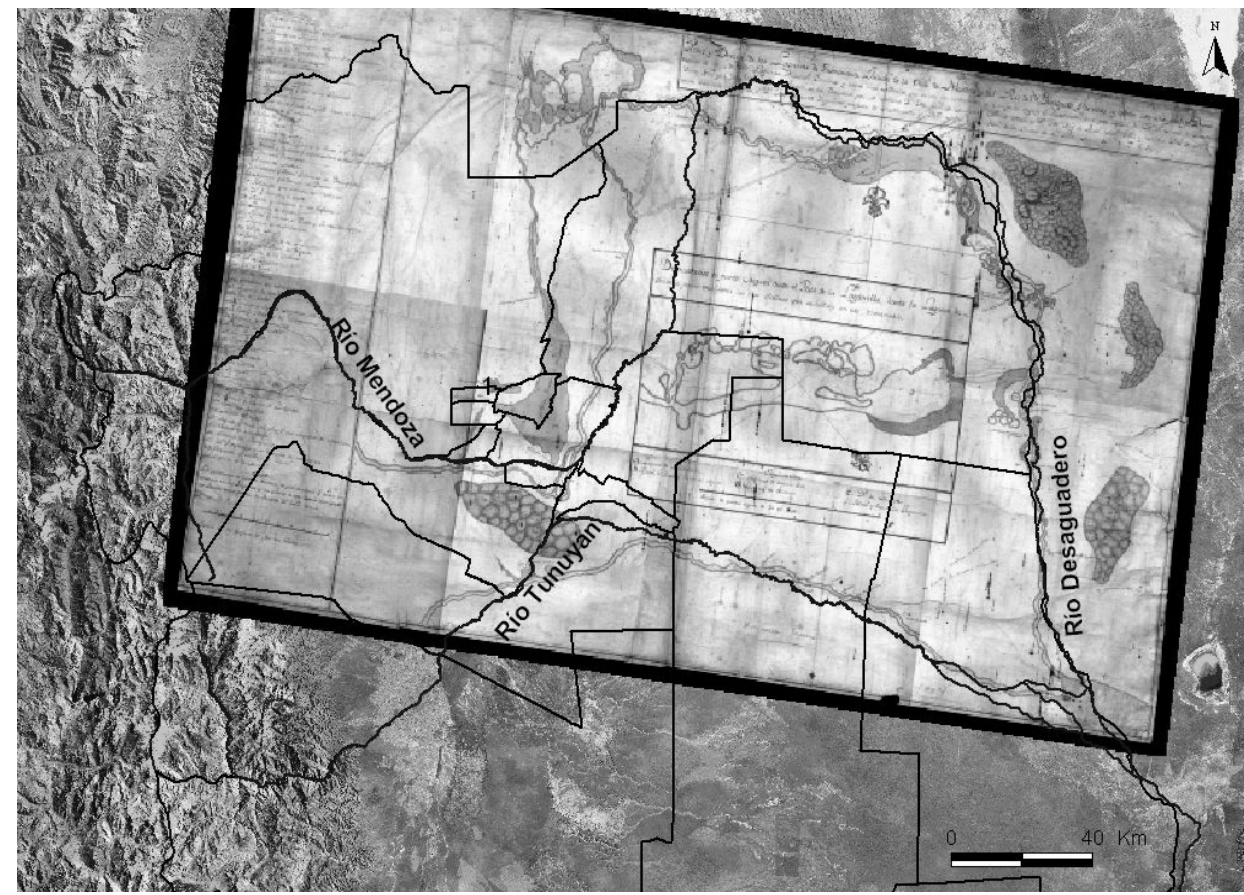

Figura 3: Superposición con georeferencia de Mapa histórico e imagen satelital 
De esta manera, si bien apuntamos a proponer el criterio ambiental para la localización de sitios arqueológicos también se logró la localización de sitios históricos mencionados explícitamente, pero mediante el uso de Geotecnología.

En este sentido, como resultado preliminar del análisis se proponen dos áreas hipotéticas para realizar tareas de prospección arqueológica en búsqueda de restos materiales de los grupos humanos que habitaron esta zona:

- El área correspondiente a la "laguna de los Chomes" (ver figura 4) ya que de acuerdo a la documentación histórica, sus integrantes fueron encomendados por los españoles (Prieto y Chiavazza, 2006).

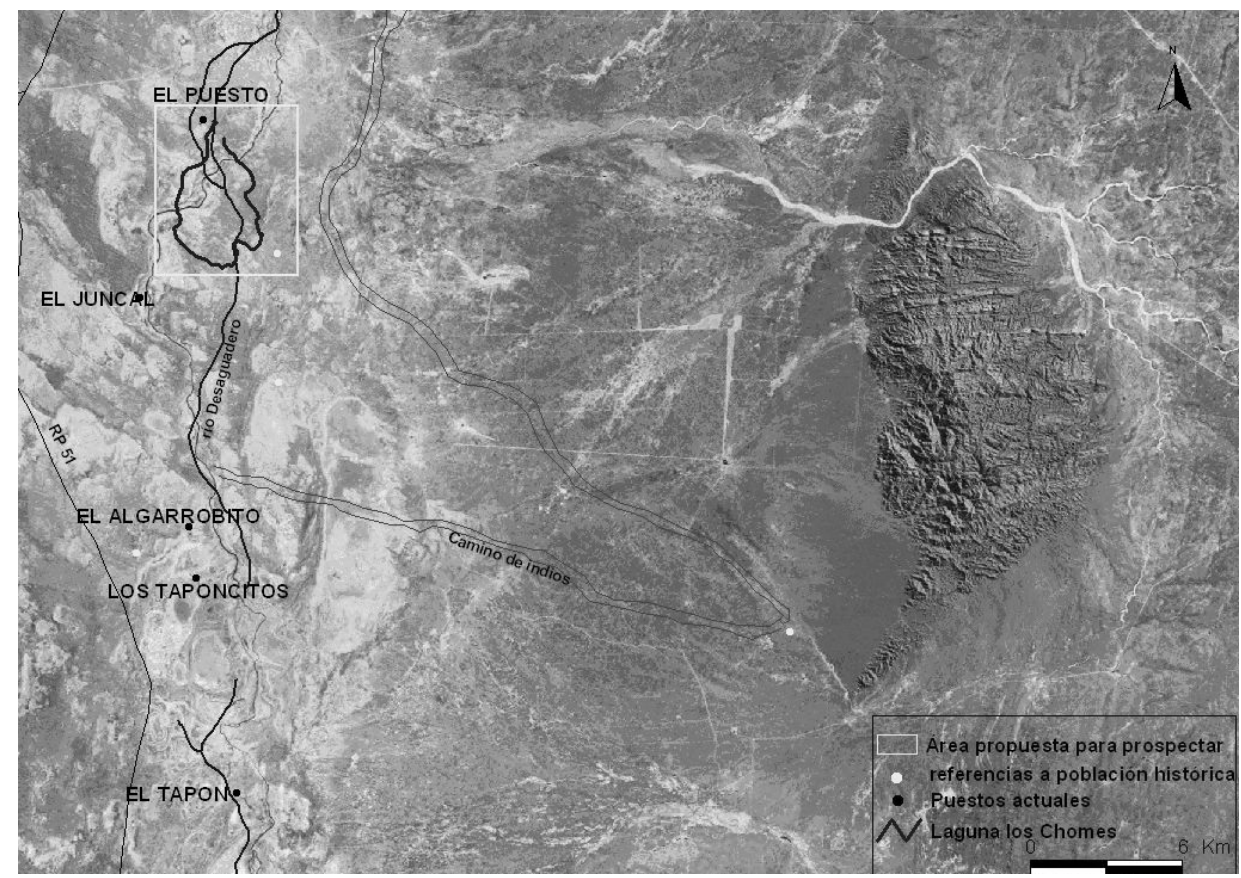

Figura 4: Imagen de satélite con referencias históricas y actuales. Resaltado el sector correspondiente a la laguna de los Chomes

- Las áreas referidas a los "pueblos de indios", mencionados en el mapa. Estos pueblos dispersos reflejan una incipiente red de centros poblados y representan una valiosa fuente de información para conocer la configuración territorial del espacio árido del nordeste, hacia fines del s. XVIII (según Chiavazza et al 2002).

El criterio ambiental utilizado para la determinación de sitios arqueológicos, arrojó resultados positivos ya que el análisis de los restos arqueológicos recuperados en los puntos arqueológicos (PA) detectados durante las tareas de prospección llevadas a cabo, en el sector del río Desaguadero, permiten reconocer la existencia de ocupaciones intensivas en un lapso de entre 1600 y 400 años AP.(Prieto y Chiavazza, op. cit.) Mientras que los restos arqueofaunísticos de pescado, armadillos y cáscaras de huevo de ñandú, recuperados en el sitio PA 57, reflejan la relación que existió entre los grupos humanos y los recursos presentes en el ambiente de llanura, lo mismo sucede con los restos líticos que muestran escaso descarte de instrumentos e intensos restos del trabajo de retoque (Prieto y Chiavazza, op. cit) 
Consideramos que la teledetección, orientada a delimitar los espacios ocupados históricamente y los recursos próximos a estos espacios, permitirá ampliar las tareas de prospección arqueológica, a la vez que otorgará nuevas técnicas de localización espacial de sitios arqueológicos.

De esta manera, el trabajo interdisciplinario entre la Arqueología, la Geografía y la Historia, permite enriquecer la interpretación y hacer más próxima la comprensión de los fenómenos espaciales y sus interacciones.

Referencias citadas

1 Por ejemplo, la revista Progress in Geography, fue dividida posteriormente en dos series distintas: Progress in Physical Geography y Progress in Human Geography. 
Bibliografía

Abraham, E. y M. R. Prieto. 1981. Enfoque Diacrónico de los Cambios Ecológicos y de las Adaptaciones Humanas en el NE. Árido Mendocino. Cuadernos del CEIFAR 8, pp.109-139. Mendoza. Actas del XV Congreso Nacional de Arqueología Argentina, 2004. Universidad Nacional de Río Cuarto, pág. $183-197$.

BARROS, C; J. NASTRI.1995. La perspectiva espacial en Arqueología. Centro Editor de América Latina, Argentina.

BOSQUE SENDRA, J. 1992. Sistemas de Información Geográfica. Ed. Rialp, Madrid. España.

BUZAI, G. 2002. Perspectivas Geodigitales del siglo XXI. En: Resúmenes de las IX jornadas cuyanas de Geografía. UNCuyo, Mendoza.

BUZAI, G. 2005. Sistemas de Información Geográfica en Argentina. Centro de Estudios Avanzados UBA. (versión digital).

CAPEL, H. 1998. Una Geografía para el siglo XX. Scripta Nova, revista electrónica de Geografía y Ciencias Sociales. NN 19. Universidad de Barcelona, 1998, España.

CARMONA J. 2004. Sistemas de Información Geográficos. (MS)

CEBALLOS GARCÍA, B. 2002. La Geohistoria, una proposición de análisis de la realidad social contemporánea en los pueblos de América Latina. En: Resúmenes de las IX Jornadas Cuyanas de Geografía. Universidad Nacional de Cuyo. Mendoza.

CHIAVAZZA, H. 2001. Las antiguas poblaciones de las arenas. Arqueología en las tierras áridas del NE mendocino. Bienes Patrimoniales, Ediciones Culturales de Mendoza, Mendoza.

CHIAVAZZA, H.; L. PUEBLA; L.FIORI; C. ORTEGA Y F. HERNÁNDEZ. 2002. Perspectiva Arqueológica territorial; relaciones ciudad desierto desde el estudio de los medanales en Lavalle: el caso de San José. En: Arqueología Histórica Argentina. Actas del Primer Congreso Nacional de Arqueología Argentina. Pp. 89- 110. Ed. Corregidor, Bs As.

CRIADO BOADO, F.1999. Del terreno al espacio: Planteamientos y Perspectivas para la Arqueología del Paisaje. Revista CAPA, N 6 , Universidad de Santiago de Compostela, España.

FIORI L.; D. CENARDO. 2002. Sistema de información geográfica para arqueología urbana en Mendoza. En: Arqueología Histórica Argentina. Actas de Primer Congreso Nacional de Arqueología Argentina Pp. 113-118. Ed. Corregidor, Bs As.

HERNANDEZ, F.; F. ROJAS. 2005. El sistema de información geográfica y su aplicación en la Arqueología Urbana de Mendoza. En Resúmenes del III Taller binacional Argentino chileno Arqueología de la Cordillera de los Andes $32^{\circ} / 40^{\circ}$ Latitud Sur. Ed. Ciencias y arte, Mendoza.

HERNANDEZ, F. 2005. Arqueología Urbana y SIG (ms)

MATTEUCCI, S. D. Y V. SCHEINSOHN. 2004. Procesamiento de imágenes, SIG y modelos ecológicos aplicados a la arqueología. Revista GeoFocus, artículo № 4, Pp. 93-109.

PRIETO, M. y H. CHIAVAZZA. 2006 Ambiente, cultura y relaciones interétnicas en el área huarpe del NE de Mendoza durante el siglo XVIII. En: Jornadas de Ciencia y Técnica. Sección póster. UNCuyo. Mendoza.

VAGAGGINI, V Y G. DEMATTEIS. 1977. El método analítico de la Geografía. Revista TERRA, № 1, Universidad Central de Venezuela. Venezuela.

VIGNATI MILCÍADES. 1953. Un diario de viaje por las Lagunas de Guanacache en el año 1789. En: Aportes al conocimiento Antropológico de la provincia de Mendoza. Notas del Museo de la Ciudad Eva Perón, Universidad Nacional de la ciudad Eva Perón, Facultad de Ciencias Naturales y Museo, Tomo XVI Antropología Nº 58-61, Eva Perón, BS AS. 